(2) Open Access Full Text Article

\title{
Association between VEGF -460T/C gene polymorphism and clinical outcomes of nasopharyngeal carcinoma treated with intensity-modulated radiation therapy
}

\author{
This article was published in the following Dove Press journal: \\ OncoTargets and Therapy \\ 15 February 2017 \\ Number of times this article has been viewed
}

Junyin Tan*

Li Jiang*

Xiaowei Cheng

Chunlin Wang

Jingshan Chen

Xiaoqing Huang

Peng Xie

Dongmei Xia

Rensheng Wang

Yong Zhang

Department of Radiotherapy, The First Affiliated Hospital, Guangxi Medical University, Nanning, Guangxi, People's Republic of China

*These authors contributed equally to this work
Correspondence: Yong Zhang Department of Radiotherapy, The First Affiliated Hospital, Guangxi Medical University, 6 Shuangyong Road, Nanning, Guangxi 53002I, People's Republic of China

Tel/fax +86 77/ 5356509

Email zhangyonggxmu@163.com

\begin{abstract}
Vascular endothelial growth factor (VEGF) is a potent angiogenic factor that plays a critical role in the development, metastasis, and recurrence of tumors. This study aims to determine the correlation of single-nucleotide polymorphisms in the VEGF gene with the prognosis of nasopharyngeal carcinoma (NPC). The VEGF $-460 \mathrm{~T} / \mathrm{C}$ gene polymorphisms in the genomic DNA of the blood samples of 338 patients with NPC were investigated through polymerase chain reaction and direct DNA sequencing. Results showed a significant association between the $-460 \mathrm{C}$-allele carriers and the aggressive forms of NPC as defined by stages N2-3 (odds ratio $=1.820,95 \%$ confidence interval $[\mathrm{CI}]$ : $1.118-2.962, P=0.015$ ). Furthermore, the VEGF -460T/C polymorphism was significantly associated with 3-year overall survival (OS), distant metastasis-free survival (DMFS), and progression-free survival (PFS) (T/C + C/C vs T/T: 3-year OS 78.8\% vs 95.1\%, $P=0.003$; 3-year DMFS 80.2\% vs 90.6\%, $P=0.036$; 3 -year PFS $73.9 \%$ vs $86.7 \%, P=0.042$ ) but was not associated with the local recurrence-free survival (LRFS) of the patients. The multivariate analysis indicated that the VEGF $-460 \mathrm{C}$-allele carrier was an independent significant prognostic factor for OS (hazard ratio [HR] 4.096, 95\% CI: 1.333-12.591, $P=0.014)$. N classification was an independent significant prognostic factor for DMFS in patients with locoregionally advanced NPC (HR 3.674, 95\% CI: 1.144-11.792, $P=0.029$ ). However, neoadjuvant chemotherapy (NACT) followed by concurrent chemoradiotherapy (CCRT) was not superior to CCRT alone in terms of the 3-year OS, LRFS, DMFS, and PFS of patients with VEGF $-460 \mathrm{~T} / \mathrm{C}$ polymorphism. In conclusion, the VEGF $-460 \mathrm{~T} / \mathrm{C}$ gene polymorphism may negatively affect the clinical outcomes of patients with NPC and may be considered a potential prognostic factor for this disease.
\end{abstract}

Keywords: vascular endothelial growth factor, gene polymorphism, nasopharyngeal carcinoma, clinical outcomes

\section{Introduction}

Nasopharyngeal carcinoma (NPC) is the most common malignancy in the epithelial lining of the nasopharynx. NPC is unique in the aspects of epidemiology because of its prominent geographic distribution. The highest incidence rates of NPC are observed in the southern part of China, especially in Guangdong and Guangxi. ${ }^{1,2}$ Radiotherapy is used as a standard treatment for NPC because of the unique anatomical position and moderate radiosensitivity of the tumor. Despite the combined applications of magnetic resonance imaging (MRI), intensity-modulated radiation therapy (IMRT), chemotherapy, and targeted therapy, treatment for NPC still fails, especially when the 
tumor is in the advanced stage. ${ }^{3}$ Hence, prognostic predictors, such as gene single-nucleotide polymorphisms (SNPs), must be developed.

The VEGF gene is located in chromosome $6 \mathrm{p} 12$ and is composed of a $14 \mathrm{~kb}$ coding region with eight exons and seven introns. This gene plays a key role in the formation of new blood vessels. ${ }^{4}$ In this regard, the VEGF gene, as a major angiogenic factor, is thought to be associated with tumor development and metastasis; inhibition of vascular endothelial growth factor (VEGF) signaling can suppress tumor growth and angiogenesis by modulating the blood flow and oxygenation of the tumors. ${ }^{5} \mathrm{VEGF}$ gene polymorphisms affect the aggressiveness and progression of NPC. ${ }^{6,7}$ However, the correlation of VEGF -460T/C gene polymorphism with the clinical outcomes in NPC has been rarely investigated. Our previous studies showed that VEGF $-460 \mathrm{~T} / \mathrm{C}$ gene polymorphism is associated with the risk of NPC in the Chinese population. ${ }^{8,9}$ Thus, we carried out a retrospective study to assess the role of VEGF $-460 \mathrm{~T} / \mathrm{C}$ gene polymorphism in the prognostic relevance by correlating it with the survival of NPC patients.

\section{Materials and methods}

\section{Patients, treatment, and follow-up}

This study included 338 patients diagnosed with NPC at the First Affiliated Hospital of Guangxi Medical University (Nanning, Guangxi Province, People's Republic of China) between December 2012 and December 2013. The inclusion criteria were as follows: 1) the initial diagnosis of NPC was determined by pathologists according to World Health Organization (WHO) classification; 2) Karnofsky performance score (KPS) $\geq 90 ; 3$ ) patients who underwent IMRT with platinum-based chemotherapy, along with regular follow-ups at our hospital; and 4) availability of peripheral blood samples. The exclusion criteria were as follows: 1) diagnosis with distant metastasis before treatment; 2) history of any other malignant disease; 3) any prior treatment for NPC; and 4) contraindications of radiotherapy. All the TNM classification was restaged according to the seventh edition of the International Union against Cancer/American Joint Committee on Cancer (UICC/AJCC) classification system. Written informed consents were obtained from all of the patients, and the research protocol was approved by the Ethical Review Committee of the First Affiliated Hospital of Guangxi Medical University. Information that can be used to identify individual participants during or after the data collection was available and can be accessed.
Each subject underwent the following pretreatment evaluations: patient history, physical examinations, hematological and biochemical profiling, chest radiography, abdominal sonography, MRI of the head and neck, and whole-body bone scan. The radiotherapy course was generally uniform. All the patients underwent definitive IMRT according to established methods. ${ }^{10}$ The patients also underwent two-tothree cycles of concurrent chemoradiotherapy (CCRT) and were administered cisplatin every 3 weeks. Neoadjuvant chemotherapy (NACT) was adopted in conjunction with CCRT in some patients. The NACT regimen comprised the administration of cisplatin with docetaxel every 3 weeks for two cycles. The chemotherapy was discontinued when the patient showed leukocyte counts lower than $3,000 / \mathrm{mm}^{3}$, or platelet count lower than $75,000 / \mathrm{mm}^{3}$. The chemotherapy was continued when the leukocyte and platelet counts reverted to the normal values.

The participants were followed up every 3 months during the first 2 years and then every 6 months thereafter, until the final follow-up or death of the participant. The follow-ups were conducted until February 2016. The median follow-up period was 31 months (range: 9-38 months). The overall survival (OS), local recurrence-free survival (LRFS), distant metastasis-free survival (DMFS), and progression-free survival (PFS) were selected as end points. OS was calculated from the date of enrollment to the date of the confirmed death (from any cause) or the last follow-up. LRFS was calculated from the date of enrollment to the date of the local recurrence or the last follow-up. DMFS was calculated from the date of enrollment to the date of the distant metastasis or the last follow-up. PFS was calculated from the date of enrollment to the date of any form of tumor progression or the last follow-up.

\section{DNA extraction and genotyping}

Genomic DNA was extracted from peripheral blood $(5 \mathrm{~mL})$ at the time of enrollment for genotyping by using a commercially available kit according to the manufacturer's instructions (Tiangen Biotech, Beijing, Co, Ltd). The selected VEGF SNP (-460T/C) was genotyped through polymerase chain reaction (PCR) and direct DNA sequencing. The PCR primers used for the VEGF $-460 \mathrm{~T} / \mathrm{C}$ were 5'-TGTGCAGACGGCAGTCACTA-3' (upstream primer) and 5'-CCCGCTACCAGCCGACTTT-3' (downstream primer). The PCR amplifications were performed in a $20 \mu \mathrm{L}$ reaction volume containing $2 \mu \mathrm{L}$ of genomic DNA, $0.6 \mu \mathrm{L}$ of each primer, $10 \mu \mathrm{L}$ of TaqMan Universal PCR Master Mix (Applied Biosystems), and $6.8 \mu \mathrm{L}$ of DNA-free water. 
PCR was performed under the following conditions: initial denaturation at $94^{\circ} \mathrm{C}$ for $4 \mathrm{~min}$, followed by 35 cycles of $30 \mathrm{~s}$ at $94^{\circ} \mathrm{C}$, annealing at $62^{\circ} \mathrm{C}$ for $30 \mathrm{~s}$, polymerization at $72^{\circ} \mathrm{C}$ for $45 \mathrm{~s}$, and final holding at $72^{\circ} \mathrm{C}$ for $2 \mathrm{~min}$. The PCR product was verified and genotyped through DNA sequencing. All the blood samples were genotyped successfully.

\section{Statistical analysis}

Chi-square test was performed to determine the association between the SNP and the clinicopathological features of the patients. The odds ratios (ORs) and their corresponding 95\% confidence intervals (CIs) were computed. Kaplan-Meier method was used to calculate the survival curves. The effect of the SNP on the clinical outcomes was assessed using the logrank test. Multivariate analyses were then performed using a Cox proportional hazards model to calculate the hazard ratios (HRs) and the corresponding 95\% CIs. All the statistical analyses were performed using the Statistical Product and Service Solutions software (SPSS; version 21.0). Two-sided $P$-values $<0.05$ were considered statistically significant.

\section{Results}

\section{Patient characteristics}

Table 1 shows the clinical characteristics of the 338 patients with NPC. The median age was 45 years (range: $13-76$ years).

Table I Patient characteristics and clinical features

\begin{tabular}{|c|c|}
\hline Patient characteristics & Number (\%) \\
\hline \multicolumn{2}{|l|}{ Gender } \\
\hline Male & $232(68.6)$ \\
\hline Female & $106(31.4)$ \\
\hline \multicolumn{2}{|l|}{ Age } \\
\hline$\leq 45$ years & $\mid 74(5 \mid .5)$ \\
\hline$>45$ years & 164 (48.5) \\
\hline \multicolumn{2}{|c|}{ UICC/AJCC clinical classification } \\
\hline II & $40(11.8)$ \\
\hline III & $99(29.3)$ \\
\hline IV & $199(58.9)$ \\
\hline \multicolumn{2}{|l|}{ T classification } \\
\hline $\mathrm{T} 2$ & $60(17.8)$ \\
\hline T3 & $83(24.5)$ \\
\hline $\mathrm{T} 4$ & 195 (57.7) \\
\hline \multicolumn{2}{|l|}{$\mathrm{N}$ classification } \\
\hline No & $40(11.8)$ \\
\hline NI & |4| (4I.7) \\
\hline N2 & |3| (38.8) \\
\hline N3 & $26(7.7)$ \\
\hline \multicolumn{2}{|l|}{ Chemotherapy regimens } \\
\hline $\mathrm{NACT}+\mathrm{CCRT}$ & $139(41.1)$ \\
\hline CCRT alone & $199(58.9)$ \\
\hline
\end{tabular}

Abbreviations: AJCC, American Joint Committee on Cancer; CCRT, concurrent chemoradiotherapy; NACT, neoadjuvant chemotherapy; UICC, International Union against Cancer.
IMRT combined with cisplatin-based chemotherapy was administered to all patients. A total of 139/338 (41.1\%) patients received NACT. During the follow-up period, 25 patients were lost to follow-up. Twenty patients developed locoregional relapse, and 41 patients presented with distant metastasis. The 20 patients with locoregional relapse comprised 10 patients with nasal or nasopharyngeal relapse and 10 patients with relapse in the base of the skull. Forty-one patients with distant metastasis included 14 patients with pulmonary metastasis, 14 patients with hepatic metastasis, 9 patients with bone metastasis, and 4 patients with metastasis to multiple organs. At the end of the follow-up, 43 patients died from different causes. The following results were obtained: 3-year OS of 87.1\%, 3-year LRFS of 93.7\%, 3-year DMFS of $85.5 \%$, and 3-year PFS of $80.5 \%$.

\section{Correlation of VEGF $-460 \mathrm{~T} / \mathrm{C}$ polymorphism with the clinical features of the patients}

The genotyping results showed that the distribution of the VEGF -460C-allele genotypes among the 338 enrolled patients included 9.2\% (31/338) CC, 37.9\% (128/338) TC, and 52.9\% (179/338) TT (homozygous wild allele). Table 2 summarizes the correlation of the VEGF -460T/C polymorphisms with the clinical features of the patients. The $-460 \mathrm{C}$-allele was significantly associated with high lymphatic metastasis, including $\mathrm{N} 2-3$ stage $(\mathrm{OR}=1.820$, 95\% CI: 1.118-2.962, $P=0.015)$. However, this allele was not significantly associated with gender, age, clinical classifications, T classifications, distant metastasis, local recurrence, and disease progression $(P>0.05)$.

\section{Associations of VEGF -460T/C gene polymorphisms with OS, LRFS, DMFS, and PFS of patients with NPC}

Patients with VEGF -460T/T, VEGF -460T/C, and VEGF $-460 \mathrm{C} / \mathrm{C}$ genotypes showed 3 -year OS of $95.1 \%$, $76.7 \%$, and $86.7 \%$, respectively $(P=0.008)$; and 3-year PFS of $86.7 \%, 70.8 \%$, and $86.7 \%$, respectively $(P=0.047)$. Furthermore, the same patients had DMFS of $90.6 \%, 79.9 \%$, and $81.7 \%$, respectively $(P=0.081)$; and LRFS of $92.8 \%$, $95.1 \%$, and $93.3 \%$, respectively $(P=0.862)$. The 3-year OS and PFS in patients with VEGF - 460T/C and VEGF - 460C/C genotypes were significantly lower than those of the patients with the VEGF $-460 \mathrm{~T} / \mathrm{T}$ genotype. The outcomes are shown in Figures 1-4.

The combined effects of the genotypes on the survival of patients with NPC were assessed. The $(\mathrm{T} / \mathrm{C}+\mathrm{C} / \mathrm{C})$ genotype 
Table 2 Relationship of VEGF -460T/C genotype and allele with the clinical characteristics of the patients

\begin{tabular}{|c|c|c|c|c|c|c|c|c|}
\hline \multirow[t]{2}{*}{ Characteristics } & \multicolumn{3}{|c|}{ Genotype } & \multirow[t]{2}{*}{ T-allele } & \multirow[t]{2}{*}{ C-allele } & \multirow[t]{2}{*}{ OR } & \multirow[t]{2}{*}{$95 \% \mathrm{Cl}$} & \multirow[t]{2}{*}{$P$-value } \\
\hline & $T / T$ & T/C & $\mathrm{C} / \mathrm{C}$ & & & & & \\
\hline Gender & & & & & & & & 0.835 \\
\hline Male & 122 & 87 & 23 & 331 & 133 & & & \\
\hline Female & 56 & 41 & 9 & 153 & 59 & 0.946 & $0.56 \mathrm{I}-1.595$ & \\
\hline Age, years & & & & & & & & 0.259 \\
\hline$\leq 45$ & 83 & 75 & 16 & 241 & 107 & & & \\
\hline$>45$ & 95 & 54 & 15 & 244 & 84 & 0.756 & $0.465-1.229$ & \\
\hline Clinical classification & & & & & & & & 0.916 \\
\hline II & 21 & 15 & 4 & 57 & 23 & & & \\
\hline III-IV & 158 & 114 & 26 & 430 & 166 & 0.960 & $0.455-2.207$ & \\
\hline T classification & & & & & & & & 0.446 \\
\hline TI-2 & 35 & 21 & 4 & 91 & 29 & & & \\
\hline T3-4 & 143 & 108 & 27 & 394 & 162 & 1.290 & $0.669-2.488$ & \\
\hline $\mathrm{N}$ classification & & & & & & & & $0.015^{*}$ \\
\hline No-I & 112 & 64 & 5 & 288 & 74 & & & \\
\hline N2-3 & 66 & 64 & 27 & 196 & 118 & 1.820 & $1.118-2.962$ & \\
\hline M classification & & & & & & & & 0.077 \\
\hline Mo & 166 & 104 & 27 & 436 & 158 & & & \\
\hline MI & 12 & 25 & 4 & 49 & 33 & 1.842 & $0.929-3.654$ & \\
\hline Local recurrence & & & & & & & & $0.74 I$ \\
\hline Yes & 12 & 6 & 2 & 30 & 10 & & & \\
\hline No & 166 & 122 & 30 & 454 & 182 & 1.192 & $0.420-3.379$ & \\
\hline Disease progression & & & & & & & & 0.158 \\
\hline Yes & 23 & 37 & 4 & 83 & 45 & & & \\
\hline No & 156 & 91 & 27 & 403 & 145 & 0.656 & $0.365-1.18 \mid$ & \\
\hline
\end{tabular}

Note: $* P<0.05$ was considered statistically significant.

Abbreviations: $\mathrm{Cl}$, confidence interval; OR, odds ratio; VEGF, vascular endothelial growth factor.

carriers had significantly lower 3-year OS, DMFS, and PFS compared with the wild-type T/T genotype carriers $(95.1 \%$ vs $78.8 \%, P=0.003$, Figure $5 ; 90.6 \%$ vs $80.2 \%, P=0.036$, Figure $6 ; 86.7 \%$ vs $73.9 \%, P=0.042$, Figure 7 , respectively). In addition, LRFS was not significantly different between $(\mathrm{T} / \mathrm{C}+\mathrm{C} / \mathrm{C})$ and $\mathrm{T} / \mathrm{T}$ genotype carriers (Figure 8 ).

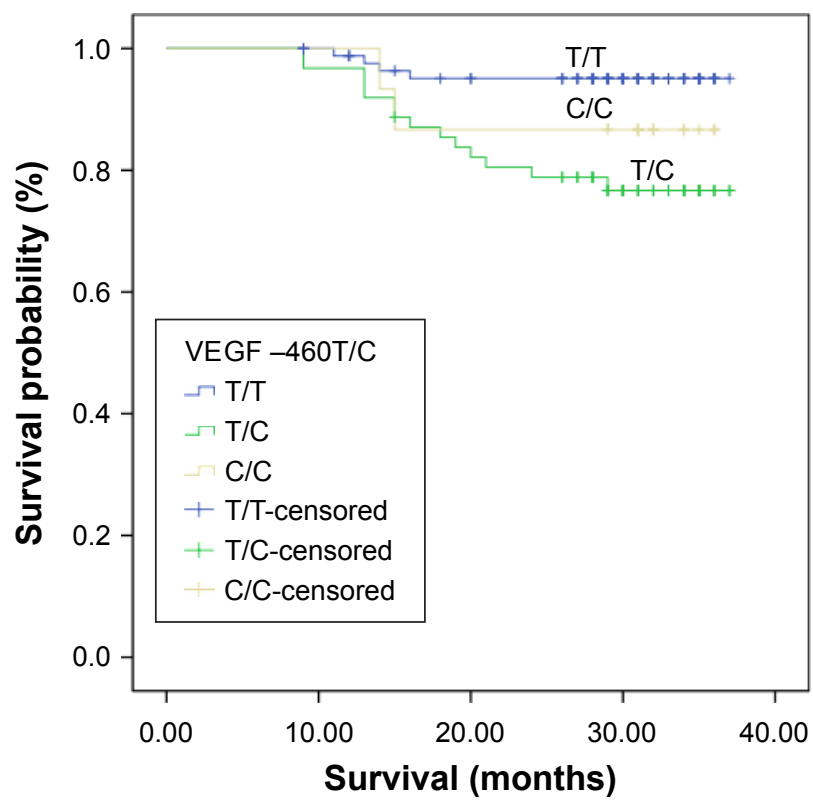

Figure I Influence of VEGF -460T/C genotypes on OS.

Abbreviations: OS, overall survival; VEGF, vascular endothelial growth factor.
Univariate and multivariate analyses for determining the prognostic factors of patients with NPC

The univariate analysis indicated that the $\mathrm{N}$ classification was associated with OS, PFS, and DMFS ( $P=0.023, P=0.008$, and $P=0.014$, respectively). Moreover, the VEGF -460

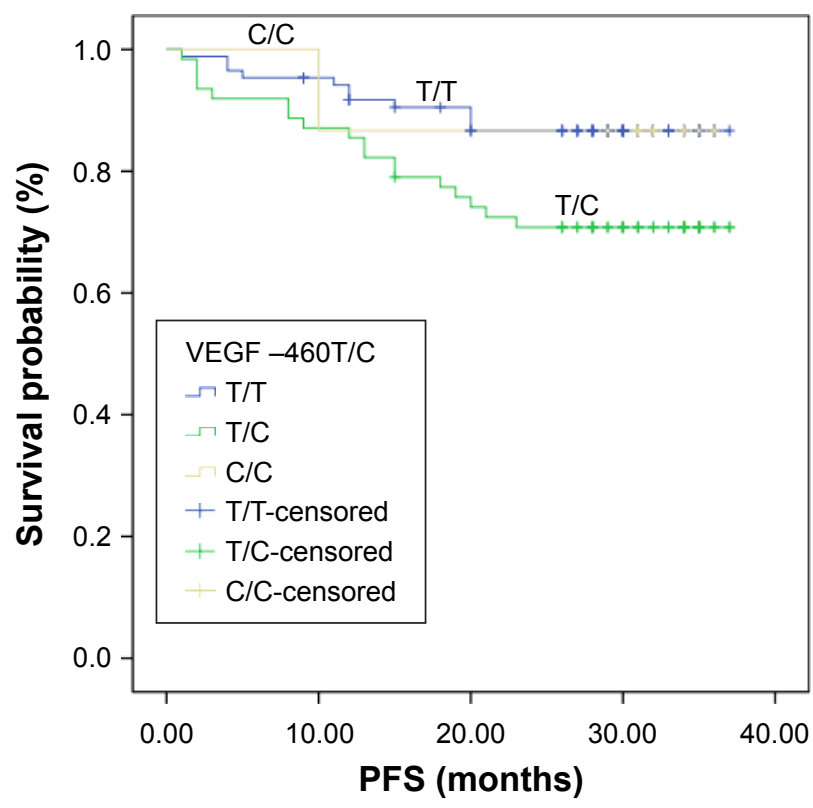

Figure 2 Influence of VEGF -460T/C genotypes on PFS.

Abbreviations: PFS, progression-free survival; VEGF, vascular endothelial growth factor. 


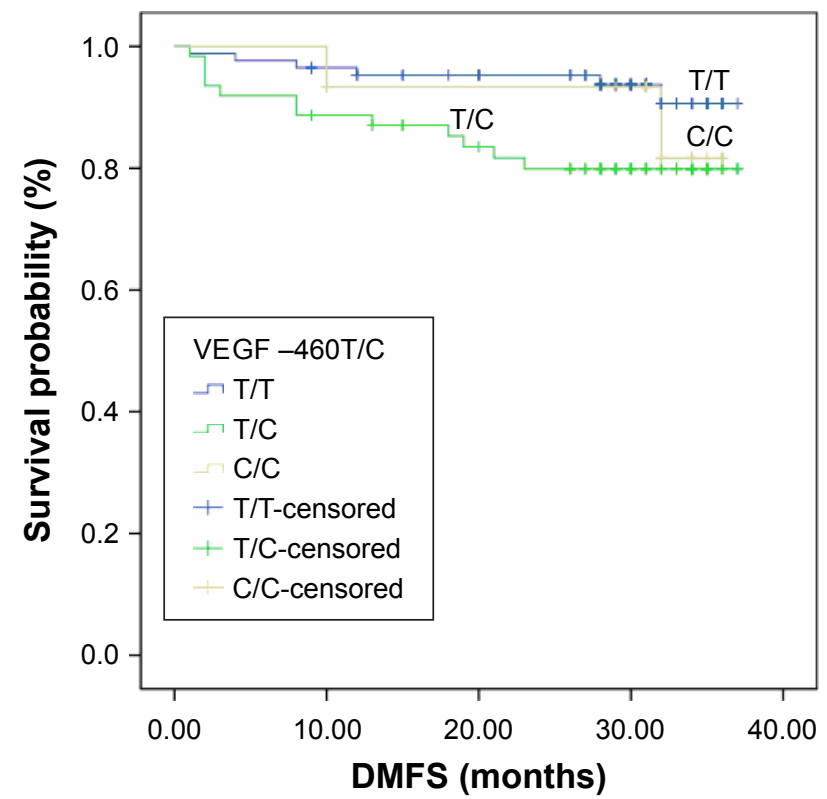

Figure 3 Influence of VEGF -460T/C genotypes on DMFS.

Abbreviations: DMFS, distant metastasis-free survival; VEGF, vascular endothelial growth factor.

SNPs were significantly associated with $\mathrm{OS}(P=0.008)$ and PFS $(P=0.047)$. Compared with the $\mathrm{T} / \mathrm{T}$ genotype, the $(\mathrm{T} / \mathrm{C}+\mathrm{C} / \mathrm{C})$ genotype was associated with PFS $(P=0.042)$, $\operatorname{DMFS}(P=0.036)$, and $\mathrm{OS}(P=0.003)$. The results are shown in Tables 3-6. Compared with patients receiving CCRT, the patients receiving NACT followed by CCRT had no significant improvement in their prognosis in terms of 3-year OS, LRFS, DMPS, and PFS in relation to the VEGF $-460 \mathrm{~T} / \mathrm{C}$ polymorphism $(P>0.05$; Table 7$)$.

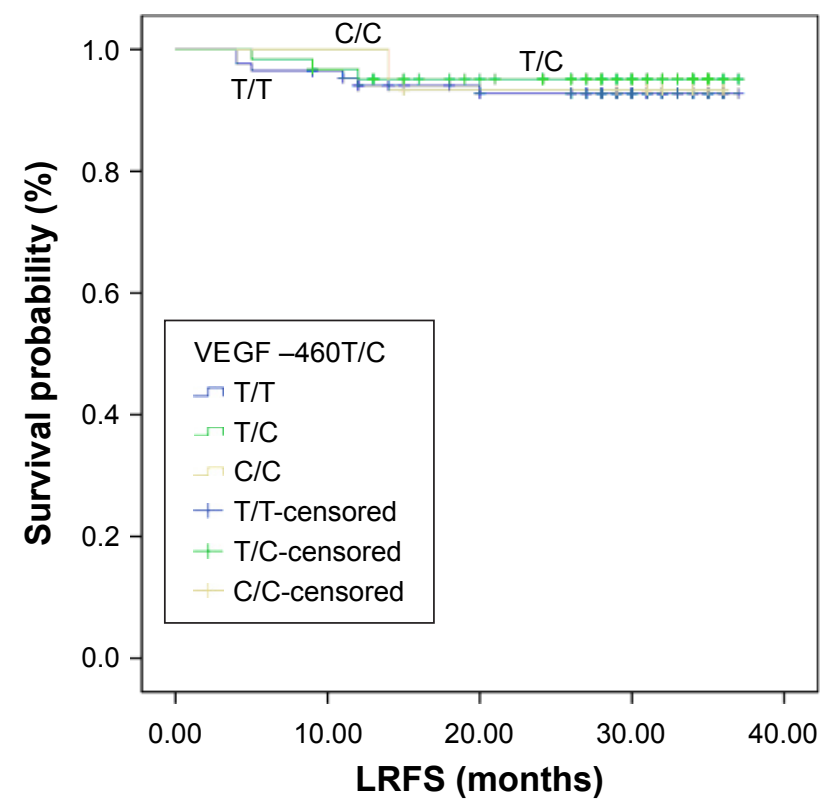

Figure 4 Influence of VEGF -460T/C genotypes on LRFS.

Abbreviations: LRFS, local recurrence-free survival; VEGF, vascular endothelial growth factor.

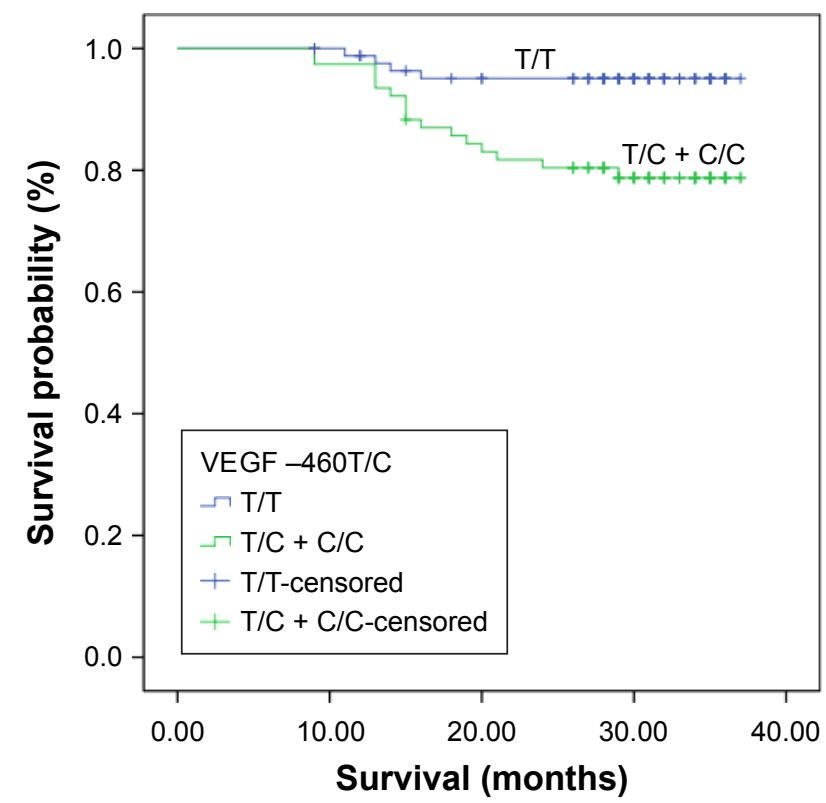

Figure 5 OS for $(T / C+C / C)$ genotype carriers and T/T genotype carriers. Abbreviations: OS, overall survival; VEGF, vascular endothelial growth factor.

The multivariate analysis results showed that the VEGF $-460 \mathrm{~T} / \mathrm{C}$ polymorphism was an independent significant prognostic factor for OS (HR 4.096, 95\% CI: 1.333-12.591, $P=0.014$ ). The N classification (N2-3 vs N0-1) was an independent significant prognostic factor for DMFS in patients with locoregionally advanced NPC (HR $3.674,95 \%$ CI: $1.144-11.792, P=0.029)$. No significant association was observed between the predictors (gender, age, clinical classifications, $\mathrm{T}$ classifications, $\mathrm{N}$ classifications,

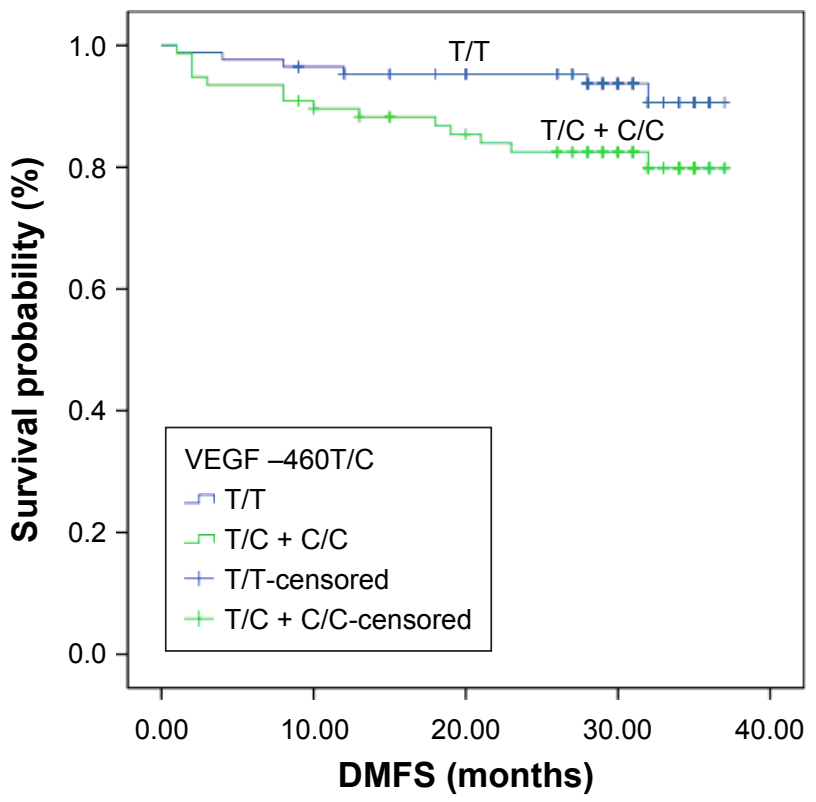

Figure 6 DMFS for $(T / C+C / C)$ genotype carriers and T/T genotype carriers. Abbreviations: DMFS, distant metastasis-free survival; VEGF, vascular endothelial growth factor. 


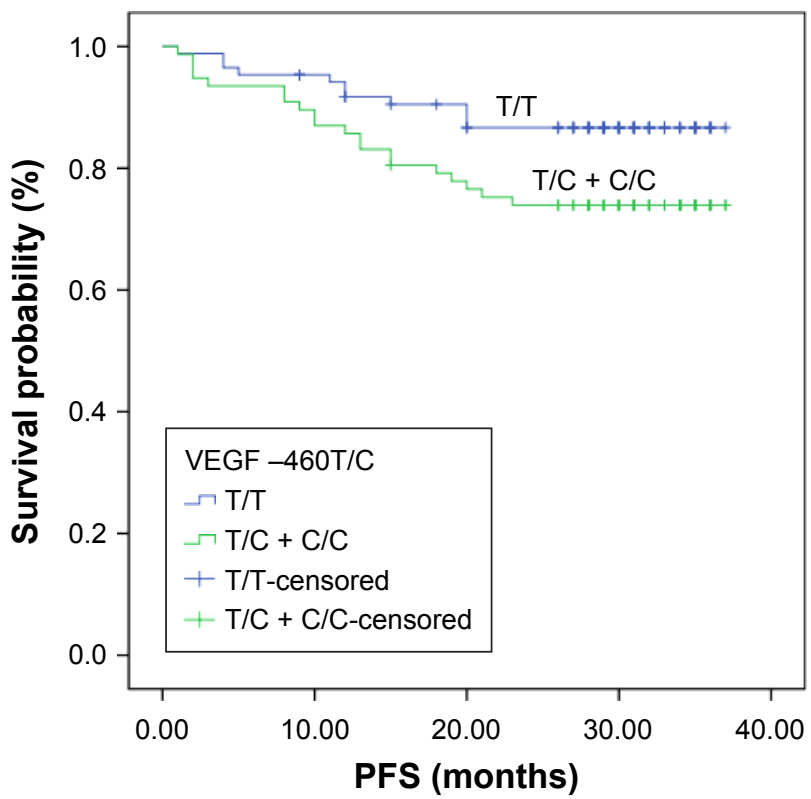

Figure 7 PFS for $(T / C+C / C)$ genotype carriers and T/T genotype carriers.

Abbreviations: PFS, progression-free survival; VEGF, vascular endothelial growth factor.

chemotherapy regimens, and VEGF -460T/C SNP) and LRFS or PFS (Table 8).

\section{Discussion}

VEGF plays a pivotal role in prompting tumor angiogenesis, metastasis, and survival through a variety of mechanisms, such as the effects on endothelial cell proliferation, survival, and migration. ${ }^{11}$ Several VEGF SNPs were reported

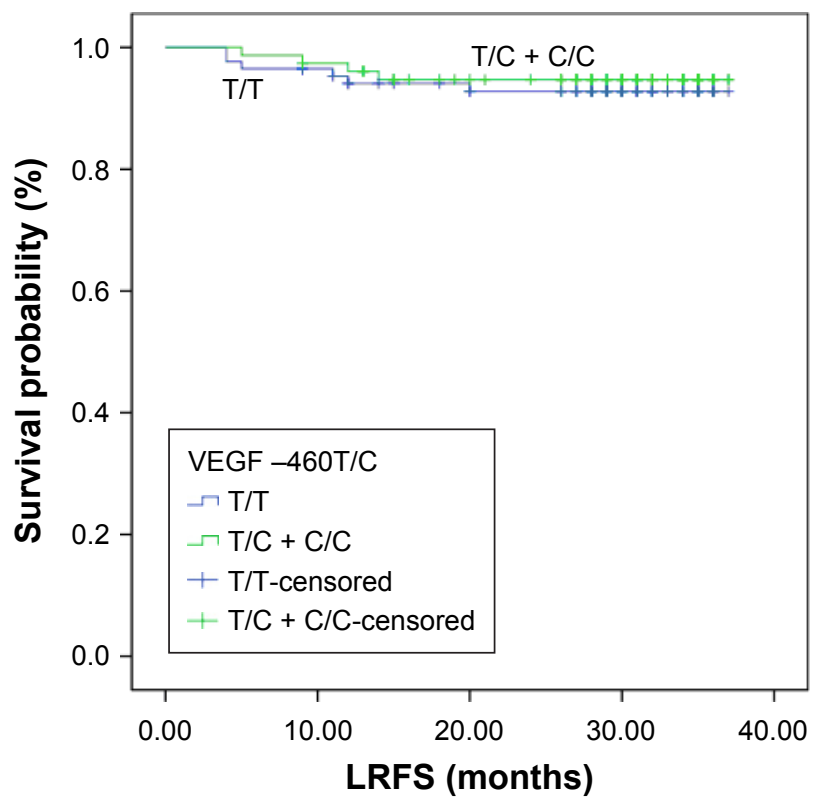

Figure 8 LRFS for (T/C + C/C) genotype carriers and T/T genotype carriers. Abbreviations: LRFS, local recurrence-free survival; VEGF, vascular endothelial growth factor.
Table 3 Univariate analysis of OS

\begin{tabular}{lllll}
\hline Variables & \multicolumn{3}{l}{ Cumulative survival } & P-value \\
\cline { 2 - 3 } & I-year OS & 2-year OS & 3-year OS & \\
\hline Gender & & & & \\
Male & $97.3 \%$ & $87.9 \%$ & $86.7 \%$ & 0.872 \\
Female & $100.0 \%$ & $87.9 \%$ & $87.9 \%$ & \\
Age, years & & & & \\
$\quad$-45 & $98.8 \%$ & $86.7 \%$ & $85.1 \%$ & 0.515 \\
$>45$ & $97.5 \%$ & $89.3 \%$ & $89.3 \%$ & \\
Clinical stage & & & & \\
II & $94.7 \%$ & $94.7 \%$ & $94.7 \%$ & 0.311 \\
III-IV & $97.9 \%$ & $88.5 \%$ & $86.0 \%$ & \\
T classification & & & & \\
T2 & $100.0 \%$ & $93.1 \%$ & $93.1 \%$ & 0.314 \\
T3-4 & $97.7 \%$ & $86.7 \%$ & $85.7 \%$ & \\
N classification & & & & \\
N0-I & $97.7 \%$ & $93.0 \%$ & $93.0 \%$ & $0.023 *$ \\
N2-3 & $98.6 \%$ & $81.8 \%$ & $79.7 \%$ & \\
Chemotherapy & & & & \\
regimens & & & & \\
NACT + CCRT & $100.0 \%$ & $87.6 \%$ & $87.6 \%$ & 0.883 \\
CCRT & $96.9 \%$ & $88.2 \%$ & $86.6 \%$ & \\
-460T/C & & & & \\
T/T & $98.8 \%$ & $95.1 \%$ & $95.1 \%$ & $0.008 *$ \\
T/C & $96.8 \%$ & $78.9 \%$ & $76.7 \%$ & \\
C/C & $100.0 \%$ & $86.7 \%$ & $86.7 \%$ & \\
T/T vs & $98.8 \%$ vs & $95.1 \%$ vs & $95.1 \%$ vs & 0.003 \\
T/C + C/C & $97.4 \%$ & $80.4 \%$ & $78.8 \%$ & \\
\hline Nete & & & \\
\hline
\end{tabular}

Note: $* P<0.05$ was considered statistically significant.

Abbreviations: CCRT, concurrent chemoradiotherapy; OS, overall survival; NACT, neoadjuvant chemotherapy.

Table 4 Univariate analysis of LRFS

\begin{tabular}{|c|c|c|c|c|}
\hline \multirow[t]{2}{*}{ Variables } & \multicolumn{3}{|c|}{ Cumulative survival } & \multirow[t]{2}{*}{$P$-value } \\
\hline & I-year LRFS & 2-year LRFS & 3-year LRFS & \\
\hline \multicolumn{5}{|l|}{ Gender } \\
\hline Male & $95.5 \%$ & $93.5 \%$ & $93.5 \%$ & 0.931 \\
\hline Female & $94.1 \%$ & $94.1 \%$ & $94.1 \%$ & \\
\hline \multicolumn{5}{|l|}{ Age, years } \\
\hline$\leq 45$ & $96.4 \%$ & $93.9 \%$ & $93.9 \%$ & 0.891 \\
\hline$>45$ & $93.5 \%$ & $93.5 \%$ & $93.5 \%$ & \\
\hline \multicolumn{5}{|l|}{ Clinical stage } \\
\hline ॥ & $100.0 \%$ & $100.0 \%$ & $100.0 \%$ & 0.238 \\
\hline III-IV & $94.4 \%$ & $92.8 \%$ & $92.8 \%$ & \\
\hline \multicolumn{5}{|l|}{$\mathrm{T}$ classification } \\
\hline $\mathrm{T} 2$ & $96.6 \%$ & $96.6 \%$ & $96.6 \%$ & 0.497 \\
\hline T3-4 & $94.7 \%$ & $93.0 \%$ & $93.0 \%$ & \\
\hline \multicolumn{5}{|l|}{$\mathrm{N}$ classification } \\
\hline N0-I & $96.5 \%$ & $96.5 \%$ & $96.5 \%$ & 0.105 \\
\hline N2-3 & $93.2 \%$ & $90.2 \%$ & $90.2 \%$ & \\
\hline \multicolumn{5}{|l|}{ Chemotherapy } \\
\hline \multicolumn{5}{|l|}{ regimens } \\
\hline $\mathrm{NACT}+\mathrm{CCRT}$ & $97.0 \%$ & $90.6 \%$ & $90.6 \%$ & 0.212 \\
\hline CCRT & $95.8 \%$ & $95.8 \%$ & $95.8 \%$ & \\
\hline \multicolumn{5}{|l|}{$-460 \mathrm{~T} / \mathrm{C}$} \\
\hline $\mathrm{T} / \mathrm{T}$ & $94.1 \%$ & $92.8 \%$ & $92.8 \%$ & 0.862 \\
\hline $\mathrm{T} / \mathrm{C}$ & $95.1 \%$ & $95.1 \%$ & $95.1 \%$ & \\
\hline $\mathrm{C} / \mathrm{C}$ & $100.0 \%$ & $93.3 \%$ & $93.3 \%$ & \\
\hline $\mathrm{T} / \mathrm{T}$ vs & $94.1 \%$ vs & $92.8 \%$ vs & $92.8 \%$ vs & 0.619 \\
\hline $\mathrm{T} / \mathrm{C}+\mathrm{C} / \mathrm{C}$ & $96.1 \%$ & $94.7 \%$ & $94.7 \%$ & \\
\hline
\end{tabular}

Note: $P<0.05$ was considered statistically significant.

Abbreviations: CCRT, concurrent chemoradiotherapy; LRFS, local recurrencefree survival; NACT, neoadjuvant chemotherapy. 
Table 5 Univariate analysis of DMFS

\begin{tabular}{|c|c|c|c|c|}
\hline \multirow[t]{2}{*}{ Variables } & \multicolumn{3}{|c|}{ Cumulative survival } & \multirow[t]{2}{*}{$P$-value } \\
\hline & I-year DMFS & 2-year DMFS & 3-year DMFS & \\
\hline \multicolumn{5}{|l|}{ Gender } \\
\hline Male & $92.8 \%$ & $88.8 \%$ & $84.5 \%$ & 0.869 \\
\hline Female & $92.2 \%$ & $90.0 \%$ & $87.4 \%$ & \\
\hline \multicolumn{5}{|l|}{ Age, years } \\
\hline$\leq 45$ & $91.7 \%$ & $87.6 \%$ & $80.2 \%$ & 0.223 \\
\hline$>45$ & $93.7 \%$ & $90.9 \%$ & $90.9 \%$ & \\
\hline \multicolumn{5}{|l|}{ Clinical stage } \\
\hline II & $97.4 \%$ & $97.4 \%$ & $85.3 \%$ & 0.709 \\
\hline III-IV & $92.3 \%$ & $88.4 \%$ & $85.8 \%$ & \\
\hline \multicolumn{5}{|c|}{$\mathrm{T}$ classification } \\
\hline $\mathrm{T} 2$ & $93.1 \%$ & $93.1 \%$ & $85.9 \%$ & 0.677 \\
\hline T3-4 & $92.5 \%$ & $88.3 \%$ & $85.5 \%$ & \\
\hline \multicolumn{5}{|c|}{$\mathrm{N}$ classification } \\
\hline No-I & $94.4 \%$ & $94.4 \%$ & $92.0 \%$ & $0.014 *$ \\
\hline N2-3 & $90.4 \%$ & $82.6 \%$ & $77.0 \%$ & \\
\hline \multirow{2}{*}{\multicolumn{5}{|c|}{$\begin{array}{l}\text { Chemotherapy } \\
\text { regimens }\end{array}$}} \\
\hline & & & & \\
\hline $\begin{array}{l}\text { NACT + } \\
\text { CCRT }\end{array}$ & $92.4 \%$ & $89.0 \%$ & $84.3 \%$ & 0.814 \\
\hline CCRT & $92.8 \%$ & $89.4 \%$ & $86.5 \%$ & \\
\hline \multicolumn{5}{|l|}{$-460 \mathrm{~T} / \mathrm{C}$} \\
\hline $\mathrm{T} / \mathrm{T}$ & $95.3 \%$ & $95.3 \%$ & $90.6 \%$ & 0.081 \\
\hline $\mathrm{T} / \mathrm{C}$ & $88.7 \%$ & $79.9 \%$ & $79.9 \%$ & \\
\hline $\mathrm{C} / \mathrm{C}$ & $93.3 \%$ & $93.3 \%$ & $81.7 \%$ & \\
\hline $\mathrm{T} / \mathrm{T}$ vs & $95.3 \%$ vs & $95.3 \%$ vs & $90.6 \%$ vs & $0.036 *$ \\
\hline $\mathrm{T} / \mathrm{C}+\mathrm{C} / \mathrm{C}$ & $89.6 \%$ & $82.5 \%$ & $80.2 \%$ & \\
\hline
\end{tabular}

Note: $* P<0.05$ was considered statistically significant.

Abbreviations: CCRT, concurrent chemoradiotherapy; DMFS, distant metastasisfree survival; NACT, neoadjuvant chemotherapy.

to be associated with variations in VEGF expression in vitro. Among these SNPs, the $-460 \mathrm{~T} / \mathrm{C}$ polymorphism is related to high VEGF expression levels. ${ }^{12-14}$ Our previous studies also revealed that the VEGF $-460 \mathrm{~T} / \mathrm{C}$ gene polymorphism is associated with the risk of NPC and lymphatic metastasis in the Chinese population. ${ }^{8}{ }^{8}$ Currently, the correlation between VEGF SNPs and NPC has been verified in a few studies. Wang et $\mathrm{al}^{6}$ demonstrated that patients with NPC harboring the $-2578 \mathrm{CC}$ genotype exhibited increased aggressiveness, large size, poor differentiation, and advanced stage of tumors compared with patients harboring the $-2578 \mathrm{~A}$-allele. Nasr et $\mathrm{al}^{7}$ found a significant association between the $-2578 \mathrm{C}$ allele carriers and aggressive forms of NPC, which were characterized by large tumors and advanced tumor stages. Furthermore, the VEGF SNPs influenced the prognosis and treatment toxicity in patients with different cancer types treated with CRT. ${ }^{15-18}$ However, the association between VEGF -460T/C gene polymorphism and the clinical outcomes in NPC treated with IMRT has been rarely investigated.

In this study, a significant association was found between the $-460 \mathrm{C}$-allele carriers and aggressive forms of NPC, which were defined by the $\mathrm{N} 2-3$ stage (OR $=1.820,95 \% \mathrm{CI}$ : 1.118-2.962, $P=0.015)$. The VEGF $-460 \mathrm{~T} / \mathrm{C}$ polymorphism
Table 6 Univariate analysis of PFS

\begin{tabular}{|c|c|c|c|c|}
\hline \multirow[t]{2}{*}{ Variables } & \multicolumn{3}{|c|}{ Cumulative survival } & \multirow[t]{2}{*}{$P$-value } \\
\hline & I-year PFS & 2-year PFS & 3-year PFS & \\
\hline \multicolumn{5}{|l|}{ Gender } \\
\hline Male & $91.0 \%$ & $83.6 \%$ & $79.8 \%$ & \multirow[t]{2}{*}{0.736} \\
\hline Female & $90.2 \%$ & $82.0 \%$ & $82.0 \%$ & \\
\hline \multicolumn{5}{|l|}{ Age, years } \\
\hline$\leq 45$ & $89.8 \%$ & $81.7 \%$ & $81.7 \%$ & \multirow[t]{2}{*}{0.816} \\
\hline$>45$ & $90.5 \%$ & $79.4 \%$ & $79.4 \%$ & \\
\hline \multicolumn{5}{|l|}{ Clinical stage } \\
\hline II & $94.7 \%$ & $94.7 \%$ & $94.7 \%$ & \multirow[t]{2}{*}{0.114} \\
\hline III-IV & $90.2 \%$ & $78.5 \%$ & $78.5 \%$ & \\
\hline \multicolumn{5}{|l|}{ T classification } \\
\hline T2 & $89.7 \%$ & $89.7 \%$ & $89.7 \%$ & \multirow[t]{2}{*}{0.196} \\
\hline T3-4 & $90.2 \%$ & $78.4 \%$ & $78.4 \%$ & \\
\hline \multicolumn{5}{|l|}{$\mathrm{N}$ classification } \\
\hline No-I & $92.2 \%$ & $88.7 \%$ & $88.7 \%$ & \multirow[t]{2}{*}{$0.008^{*}$} \\
\hline N2-3 & $87.7 \%$ & $70.7 \%$ & $70.7 \%$ & \\
\hline \multicolumn{5}{|l|}{ Chemotherapy } \\
\hline \multicolumn{5}{|l|}{ regimens } \\
\hline $\mathrm{NACT}+\mathrm{CCRT}$ & $89.3 \%$ & $76.8 \%$ & $76.8 \%$ & \multirow[t]{2}{*}{0.433} \\
\hline CCRT & $88.6 \%$ & $83.1 \%$ & $83.1 \%$ & \\
\hline \multicolumn{5}{|l|}{$-460 \mathrm{~T} / \mathrm{C}$} \\
\hline $\mathrm{T} / \mathrm{T}$ & $93.7 \%$ & $86.7 \%$ & $86.7 \%$ & \multirow[t]{3}{*}{$0.047^{*}$} \\
\hline $\mathrm{T} / \mathrm{C}$ & $85.5 \%$ & $70.8 \%$ & $70.8 \%$ & \\
\hline $\mathrm{C} / \mathrm{C}$ & $86.7 \%$ & $86.7 \%$ & $86.7 \%$ & \\
\hline $\mathrm{T} / \mathrm{T}$ vs & $93.7 \%$ vs & $86.7 \%$ vs & $86.7 \%$ vs & $0.042^{*}$ \\
\hline $\mathrm{T} / \mathrm{C}+\mathrm{C} / \mathrm{C}$ & $85.7 \%$ & $73.9 \%$ & $73.9 \%$ & \\
\hline
\end{tabular}

Note: $* P<0.05$ was considered statistically significant.

Abbreviations: CCRT, concurrent chemoradiotherapy; NACT, neoadjuvant chemotherapy; PFS, progression-free survival.

was significantly associated with 3-year OS, 3-year DMFS, and 3-year PFS (T/C + C/C vs T/T: 3-year OS 78.8\% vs 95.1\%, $P=0.003$; 3-year DMFS $80.2 \%$ vs $90.6 \%, P=0.036$; 3 -year PFS $73.9 \%$ vs $86.7 \%, P=0.042$ ) but was not associated with LRFS. The VEGF -460C-allele carrier $(\mathrm{T} / \mathrm{C}+\mathrm{C} / \mathrm{C})$ was an independent significant prognostic factor for the 3-year OS according to the multivariate analysis results (HR 4.096, 95\% CI: $1.333-12.591, P=0.014)$. Our results might support the correlation between the polymorphisms in the VEGF -460T/C gene and poor clinical outcomes of NPC. Our results on the VEGF -460T/C SNP are consistent with the findings of previous studies on different cancer types. An in vitro study demonstrated that the VEGF $-460 \mathrm{~T} / \mathrm{C}$ SNP is located in the promoter region and may play a role in the promoter activity. Thus, the VEGF -460C-allele may increase VEGF expression and thus may promote abnormal tumor angiogenesis and growth. ${ }^{13}$ High VEGF levels in the tumor microenvironment may cause rapid cancer progression and increased resistance of the tumors to radiotherapy and chemotherapy. Chen et al ${ }^{12}$ reported that patients with colorectal cancer harboring the VEGF -460T/C and VEGF -460C/C genotypes had significantly higher circulating VEGF levels, more aggressive tumor behavior, and lower chemotherapy sensitivity and prognosis than those with the wild-type T/T genotype; furthermore, the VEGF -460T/C gene polymorphisms were considered 
Table 7 The 3-year OS, LRFS, DMFS, and PFS in the VEGF -460T/C genotype subgroups after chemotherapy regimens

\begin{tabular}{|c|c|c|c|c|c|c|c|c|c|c|c|c|}
\hline \multirow{2}{*}{$\begin{array}{l}-460 \mathrm{~T} / \mathrm{C} \\
\text { genotype }\end{array}$} & \multicolumn{2}{|c|}{ 3-year OS } & \multirow[t]{2}{*}{$P$-value } & \multicolumn{2}{|c|}{ 3-year LRFS } & \multirow[t]{2}{*}{$P$-value } & \multicolumn{2}{|c|}{ 3-year DMFS } & \multirow[t]{2}{*}{$P$-value } & \multicolumn{2}{|c|}{ 3-year PFS } & \multirow[t]{2}{*}{$P$-value } \\
\hline & $\begin{array}{l}\text { NACT + } \\
\text { CCRT }\end{array}$ & $\overline{\text { CCRT }}$ & & $\begin{array}{l}\text { NACT + } \\
\text { CCRT }\end{array}$ & $\overline{\text { CCRT }}$ & & $\begin{array}{l}\text { NACT + } \\
\text { CCRT }\end{array}$ & $\overline{\text { CCRT }}$ & & $\begin{array}{l}\text { NACT + } \\
\text { CCRT }\end{array}$ & $\overline{\text { CCRT }}$ & \\
\hline$T / T$ & $93.9 \%$ & $95.9 \%$ & 0.707 & $88.0 \%$ & $96.1 \%$ & 0.173 & $84.7 \%$ & $96.2 \%$ & 0.238 & $84.9 \%$ & $87.9 \%$ & 0.754 \\
\hline $\mathrm{T} / \mathrm{C}$ & $79.5 \%$ & $74.6 \%$ & 0.700 & $96.0 \%$ & $94.7 \%$ & 0.7815 & $81.8 \%$ & $78.1 \%$ & 0.587 & $63.3 \%$ & $75.7 \%$ & 0.420 \\
\hline $\mathrm{C} / \mathrm{C}$ & $85.7 \%$ & $87.5 \%$ & $0.88 I$ & $85.7 \%$ & $100.0 \%$ & 0.285 & $85.7 \%$ & $75.0 \%$ & 0.962 & $85.7 \%$ & $87.5 \%$ & 0.922 \\
\hline $\mathrm{T} / \mathrm{C}+\mathrm{C} / \mathrm{C}$ & $80.9 \%$ & $80.0 \%$ & 0.720 & $93.6 \%$ & $95.6 \%$ & 0.760 & $83.1 \%$ & $76.8 \%$ & 0.597 & $68.4 \%$ & $77.8 \%$ & 0.469 \\
\hline
\end{tabular}

Note: $P<0.05$ was considered statistically significant.

Abbreviations: CCRT, concurrent chemoradiotherapy; DMFS, distant metastasis-free survival; LRFS, local recurrence-free survival; NACT, neoadjuvant chemotherapy; OS, overall survival; PFS, progression-free survival; VEGF, vascular endothelial growth factor.

independent predictors of recurrence and prognosis in colorectal cancer. Masago et $\mathrm{al}^{19}$ also reported that the VEGF $-460 \mathrm{CC}$ genotype had a negative prognostic effect on the survival of patients with advanced-stage non-small-cell lung cancer. Further, the survival rates of patients with NPC and overexpressed VEGF in tumor tissues were significantly lower than those of the patients with low VEGF expression. ${ }^{20}$ By contrast, Lv et $\mathrm{al}^{21}$ reported that elevated serum VEGF expression in patients with NPC was closely associated with DMFS and OS but was not significantly associated with LRFS. The correlation between VEGF and local recurrence of NPC after radiotherapy remains unclear. Radiotherapy could promote VEGF expression and enhance tumor angiogenesis, which may contribute to the radioresistance of NPC in mouse xenograft models. Therefore, radiotherapy combined with anti-VEGF therapy may effectively decrease radiation resistance. ${ }^{22}$ Our study also showed no significant association between LRFS and VEGF $-460 \mathrm{~T} / \mathrm{C}$ polymorphism. This finding mainly stems from the

Table 8 Multivariate analysis of OS, DMFS, LRFS, and PFS

\begin{tabular}{|c|c|c|c|}
\hline Variables & HR & $95 \% \mathrm{Cl}$ & $P$-value \\
\hline \multicolumn{4}{|l|}{ Results of the multivariate analysis of OS } \\
\hline Gender (female vs male) & 1.149 & $0.412-3.205$ & 0.790 \\
\hline Age ( $>45$ vs $\leq 45$ years) & 0.967 & $0.379-2.466$ & 0.944 \\
\hline T classification (T3-4 vs T2) & 1.671 & $0.203-13.786$ & 0.633 \\
\hline $\mathrm{N}$ classification (N2-3 vs N0-I) & 2.490 & $0.840-7.377$ & 0.100 \\
\hline Chemotherapy (CCRT vs NACT + CCRT) & 1.169 & $0.450-3.036$ & 0.749 \\
\hline VEGF $-460 \mathrm{~T} / \mathrm{C}$ SNP $(\mathrm{T} / \mathrm{C}+\mathrm{C} / \mathrm{C}$ vs T/T) & 4.096 & $|.333-12.59|$ & $0.014^{*}$ \\
\hline \multicolumn{4}{|l|}{ Results of the multivariate analysis of DMFS } \\
\hline Gender (female vs male) & 1.169 & $0.422-3.241$ & 0.764 \\
\hline Age ( $>45$ vs $\leq 45$ years) & 0.667 & $0.254-1.747$ & 0.409 \\
\hline T classification (T3-4 vs T2) & 1.906 & $0.232-15.688$ & 0.549 \\
\hline $\mathrm{N}$ classification (N2-3 vs N0-I) & 3.674 & I.I44-II.792 & $0.029 *$ \\
\hline Chemotherapy (CCRT vs NACT + CCRT) & 1.004 & $0.390-2.585$ & 0.994 \\
\hline VEGF $-460 \mathrm{~T} / \mathrm{C}$ SNP $(\mathrm{T} / \mathrm{C}+\mathrm{C} / \mathrm{C}$ vs $\mathrm{T} / \mathrm{T})$ & 2.442 & $0.9|3-6.53|$ & 0.075 \\
\hline \multicolumn{4}{|l|}{ Results of the multivariate analysis of LRFS } \\
\hline Gender (female vs male) & 0.848 & $0.203-3.543$ & 0.821 \\
\hline Age ( $>45$ vs $\leq 45$ years) & 1.338 & $0.367-4.872$ & 0.659 \\
\hline $\mathrm{T}$ classification (T3-4 vs T2) & 0.892 & $0.096-8.257$ & 0.920 \\
\hline $\mathrm{N}$ classification (N2-3 vs N0-I) & 2.449 & $0.600-10.002$ & 0.212 \\
\hline Chemotherapy (CCRT vs NACT + CCRT) & 0.434 & $0.114-1.654$ & 0.222 \\
\hline VEGF $-460 \mathrm{~T} / \mathrm{C}$ SNP $(\mathrm{T} / \mathrm{C}+\mathrm{C} / \mathrm{C}$ vs $\mathrm{T} / \mathrm{T})$ & 0.708 & $0.185-2.713$ & 0.614 \\
\hline \multicolumn{4}{|l|}{ Results of the multivariate analysis of PFS } \\
\hline Gender (female vs male) & 0.922 & $0.404-2.101$ & 0.846 \\
\hline Age ( $>45$ vs $\leq 45$ years) & 1.210 & $0.58 I-2.518$ & 0.610 \\
\hline$T$ classification (T3-4 vs T2) & 1.152 & $0.253-5.238$ & 0.855 \\
\hline $\mathrm{N}$ classification (N2-3 vs N0-I) & 2.189 & $0.967-4.956$ & 0.060 \\
\hline Chemotherapy (CCRT vs NACT + CCRT) & 0.763 & $0.360-1.616$ & 0.480 \\
\hline VEGF $-460 T / C$ SNP $(T / C+C / C$ vs $T / T)$ & 2.023 & $0.937-4.368$ & 0.073 \\
\hline
\end{tabular}

Note: $* P<0.05$ was considered statistically significant.

Abbreviations: CCRT, concurrent chemoradiotherapy; Cl, confidence interval; DMFS, distant metastasis-free survival; HR, hazard ratio; LRFS, local recurrence-free survival; NACT, neoadjuvant chemotherapy; OS, overall survival; PFS, progression-free survival; SNP, single-nucleotide polymorphism; VEGF, vascular endothelial growth factor. 
following factors: first, despite more than $80 \%$ of the patients being at the T3-4 stage, the application of IMRT and combined CRT greatly improved the local control of the patients, resulting in 3-year LRFS of more than $90 \%$. This effect might be a major reason that the VEGF SNP cannot attain significant effectiveness on LRFS. Second, we only focused on a single functional promoter VEGF SNP, and the results are not comprehensive. The result might have been influenced by the interference caused by the genetic linkages with other functional SNPs. Finally, we assumed that the VEGF -460T/C possessed some additional unknown biological functions. In summary, the VEGF $-460 \mathrm{~T} / \mathrm{C}$ polymorphism may play a critical role in lymph node involvement, distant metastasis, and poor prognosis by promoting angiogenesis in NPC. The VEGF - 460T/C polymorphism is thus a valuable prognostic marker for patients with NPC. However, the generalizability of our study is limited because we did not directly detect VEGF expression in tumor cells or evaluate the serum VEGF levels in the patients.

IMRT, which is widely used for patients with NPC, delivers a high radiation dose to tumors while maintaining a safe dose to normal tissues surrounding the tumor. This technique also exhibits excellent tumor coverage. Despite these advantages and the improved locoregional control with IMRT, patients are still at high risk of systemic failure and radioresistance. ${ }^{10}$ Thus, a combined modality therapy is necessary. In our study, the VEGF $-460 \mathrm{C}$-allele carrier $(\mathrm{T} / \mathrm{C}+\mathrm{CC})$ was regarded as an inferior prognostic factor of survival according to IMRT. As such, we evaluated the influence of combining NACT with CCRT. Our results showed that the combination could not prolong 3-year OS, LRFS, DMFS, and PFS of the patients relative to those treated with CCRT alone. NACT did not improve the survival of the VEGF -460C-allele carriers in NPC, and the role of NACT remains unclear. Song et $\mathrm{al}^{23}$ also reported that the application of NACT followed by CCRT did not show superior effectiveness, compared with CCRT alone, in patients with NPC because NACT can increase the risk of locoregional recurrences. Qiu et $\mathrm{al}^{24}$ found that survival rates of patients treated with combined NACT and IMRT were not significantly different from those treated with CCRT plus adjuvant chemotherapy (AC). Meta-analysis results confirmed that integrating NACT to CCRT significantly improved PFS and OS, in contrast to CCRT with or without AC in locoregionally advanced NPC; however, an increased chance of developing acute toxicity, such as grade 3-4 anemia, thrombocytopenia, leukopenia, and fatigue, was observed. ${ }^{25}$ Recently, a combined radiotherapy and antiangiogenic therapy has been proposed and considered as a promising method for treatment of NPC. On the one hand, the proliferation and metastasis of tumor cells rely on angiogenesis induced by VEGF. On the other hand, rapidly growing tumors cause hypoxia, which upregulates VEGF, thereby promoting tumor proliferation, angiogenesis, and increased radioresistance. Thus, treatment that targets tumor angiogenesis can modulate the tumor microenvironment and thus can improve tumor blood flow and oxygenation, leading to enhanced radiosensitivity. ${ }^{5}$ Bevacizumab, a recombinant humanized monoclonal antibody against VEGF, has progressed into clinical trials for different tumor types, and has a promising future. ${ }^{26-28}$ Some studies also demonstrated that antiangiogenic therapy can normalize tumor vasculature and enhance radiation responses in xenografted human NPC models. ${ }^{29,30}$ The therapies that combine antiangiogenic therapy and radiotherapy might be promising strategies to inhibit angiogenesis and prevent adverse NPC outcomes. The result of our study must be viewed cautiously because of some limitations. Particularly, the number of participants was not sufficient, and the details of the underlying mechanisms were not investigated. Thus, our results must be validated and analyzed using larger sample sizes.

\section{Conclusion}

This study demonstrated that the VEGF $-460 \mathrm{~T} / \mathrm{C}$ polymorphism was associated with poor clinical outcomes in patients with NPC. The VEGF $-460 \mathrm{~T} / \mathrm{C}$ polymorphism may be a potential prognostic indicator for patients with NPC and a promising target for treatment. Further studies must determine the effect of VEGF gene polymorphisms associated with combined modality therapy on NPC.

\section{Acknowledgment}

The authors thank the staff of The First Affiliated Hospital of Guangxi Medical University for providing the samples and clinical information.

\section{Author contributions}

Yong Zhang, Li Jiang, and Junyin Tan conceived and designed the study. Xiaowei Cheng, Chunlin Wang, Jingshan Chen, and Xiaoqing Huang performed the experiments. Dongmei Xia, Peng Xie, and Rensheng Wang analyzed the data. Junyin Tan, Li Jiang, and Yong Zhang wrote the paper. All authors contributed toward data analysis, drafting and critically revising the paper, gave final approval of the version to be published, and agree to be accountable for all aspects of the work.

\section{Disclosure}

The authors report no conflicts of interest in this work. 


\section{References}

1. Yu MC, Yuan JM. Epidemiology of nasopharyngeal carcinoma. Semin Cancer Biol. 2002;12(6):421-429.

2. Chua ML, Wee JT, Hui EP, Chan AT. Nasopharyngeal carcinoma. Lancet. 2016;387(10022):1012-1024.

3. Rottey S, Madani I, Deron P, Van Belle S. Modern treatment for nasopharyngeal carcinoma: current status and prospects. Curr Opin Oncol. 2011;23(3):254-258.

4. Ferrara N. Vascular endothelial growth factor and the regulation of angiogenesis. Recent Prog Horm Res. 2000;55:15-35. [discussion 16-35].

5. Hsu HW, Wall NR, Hsueh CT, et al. Combination antiangiogenic therapy and radiation in head and neck cancers. Oral Oncol. 2014; 50(1):19-26.

6. Wang T, Hu K, Ren J, Zhu Q, Wu G, Peng G. Polymorphism of VEGF$2578 \mathrm{C} / \mathrm{A}$ associated with the risk and aggressiveness of nasopharyngeal carcinoma in a Chinese population. Mol Biol Rep. 2010;37(1):59-65.

7. Nasr HB, Chahed K, Bouaouina N, Chouchane L. Functional vascular endothelial growth factor $-2578 \mathrm{C} / \mathrm{A}$ polymorphism in relation to nasopharyngeal carcinoma risk and tumor progression. Clin Chim Acta. 2008;395(1-2):124-129.

8. Xiaowei Cheng LJ, Jingshan C, Yong Z. Interaction between VEGF$1154 \mathrm{G} / \mathrm{A}$ gene polymorphism and EB virus in nasopharyngeal carcinoma. Guangxi Med J. 2014;36(3):277-280.

9. Xiaowei Cheng CW, Xiaoqing H, Yong Z. VEGF gene promoter region-460 T/C single nucleotide polymorphisms and nasopharyngeal carcinoma susceptibility in Guangxi population. Cancer Res Prevent Treat. 2014;41(10):1125-1128.

10. Wu F, Wang R, Lu H, et al. Concurrent chemoradiotherapy in locoregionally advanced nasopharyngeal carcinoma: treatment outcomes of a prospective, multicentric clinical study. Radiother Oncol. 2014; 112(1):106-111.

11. Ferrara N. Vascular endothelial growth factor: basic science and clinical progress. Endocr Rev. 2004;25(4):581-611.

12. Chen MH, Tzeng $\mathrm{CH}$, Chen PM, et al. VEGF $-460 \mathrm{~T} \rightarrow \mathrm{C}$ polymorphism and its association with VEGF expression and outcome to FOLFOX-4 treatment in patients with colorectal carcinoma. Pharmacogenomics $J$. 2011;11(3):227-236.

13. Stevens A, Soden J, Brenchley PE, Ralph S, Ray DW. Haplotype analysis of the polymorphic human vascular endothelial growth factor gene promoter. Cancer Res. 2003;63(4):812-816.

14. Shahbazi M, Fryer AA, Pravica V, et al. Vascular endothelial growth factor gene polymorphisms are associated with acute renal allograft rejection. J Am Soc Nephrol. 2002;13(1):260-264.

15. Yin M, Liao Z, Yuan X, et al. Polymorphisms of the vascular endothelial growth factor gene and severe radiation pneumonitis in non-small cell lung cancer patients treated with definitive radiotherapy. Cancer Sci. 2012;103(5):945-950.

16. Langsenlehner T, Thurner EM, Renner W, Gerger A, Kapp KS, Langsenlehner U. Association of genetic variants in VEGF-A with clinical recurrence in prostate cancer patients treated with definitive radiotherapy. Strahlenther Onkol. 2014;190(4):364-369.

17. Sakaeda T, Yamamori M, Kuwahara A, et al. VEGF G-1154A is predictive of severe acute toxicities during chemoradiotherapy for esophageal squamous cell carcinoma in Japanese patients. Ther Drug Monit. 2008; 30(4):497-503.

OncoTargets and Therapy

\section{Publish your work in this journal}

OncoTargets and Therapy is an international, peer-reviewed, open access journal focusing on the pathological basis of all cancers, potential targets for therapy and treatment protocols employed to improve the management of cancer patients. The journal also focuses on the impact of management programs and new therapeutic agents and protocols on

Submit your manuscript here: http://www.dovepress.com/oncotargets-and-therapy-journal
18. Guan X, Yin M, Wei Q, et al. Genotypes and haplotypes of the VEGF gene and survival in locally advanced non-small cell lung cancer patients treated with chemoradiotherapy. BMC Cancer. 2010;10:431.

19. Masago K, Fujita S, Kim YH, et al. Effect of vascular endothelial growth factor polymorphisms on survival in advanced-stage non-small-cell lung cancer. Cancer Sci. 2009;100(10):1917-1922.

20. Li YH, Hu CF, Shao Q, et al. Elevated expressions of survivin and VEGF protein are strong independent predictors of survival in advanced nasopharyngeal carcinoma. J Transl Med. 2008;6:1.

21. Lv X, Xiang YQ, Cao SM, et al. Prospective validation of the prognostic value of elevated serum vascular endothelial growth factor in patients with nasopharyngeal carcinoma: more distant metastases and shorter overall survival after treatment. Head Neck. 2011;33(6):780-785.

22. Zhou J, Wang L, Xu X, Tu Y, Qin S, Yin Y. Antitumor activity of Endostar combined with radiation against human nasopharyngeal carcinoma in mouse xenograft models. Oncol Lett. 2012;4(5):976-980.

23. Song JH, Wu HG, Keam BS, et al. The role of neoadjuvant chemotherapy in the treatment of nasopharyngeal carcinoma: a multi-institutional retrospective study (KROG 11-06) using propensity score matching analysis. Cancer Res Treat. 2016;48(3):917-927.

24. Qiu WZ, Huang PY, Shi JL, Xia HQ, Zhao C, Cao KJ. Neoadjuvant chemotherapy plus intensity-modulated radiotherapy versus concurrent chemoradiotherapy plus adjuvant chemotherapy for the treatment of locoregionally advanced nasopharyngeal carcinoma: a retrospective controlled study. Chin J Cancer. 2016;35:2.

25. Wang M, Tian H, Li G, et al. Significant benefits of adding neoadjuvant chemotherapy before concurrent chemoradiotherapy for locoregionally advanced nasopharyngeal carcinoma: a meta-analysis of randomized controlled trials. Oncotarget. 2016;7(30):48375-48390.

26. Cao R, Zhang S, Ma D, Hu L. A multi-center randomized phase II clinical study of bevacizumab plus irinotecan, 5-fluorouracil, and leucovorin (FOLFIRI) compared with FOLFIRI alone as second-line treatment for Chinese patients with metastatic colorectal cancer. Med Oncol. 2015;32(1):325.

27. Weathers SP, Han X, Liu DD, et al. A randomized phase II trial of standard dose bevacizumab versus low dose bevacizumab plus lomustine (CCNU) in adults with recurrent glioblastoma. $J$ Neurooncol. 2016; 129(3):487-494.

28. Matikas A, Kentepozidis N, Ardavanis A, et al. Efficacy and tolerance of frontline bevacizumab-based chemotherapy for advanced non-small cell lung cancer patients: a multicenter, phase IV study of the Hellenic Oncology Research Group (HORG). Cancer Chemother Pharmacol. 2016;78(2):369-376.

29. Peng F, Xu Z, Wang J, et al. Recombinant human endostatin normalizes tumor vasculature and enhances radiation response in xenografted human nasopharyngeal carcinoma models. PLoS One. 2012;7(4):e34646.

30. Wen QL, Meng MB, Yang B, et al. Endostar, a recombined humanized endostatin, enhances the radioresponse for human nasopharyngeal carcinoma and human lung adenocarcinoma xenografts in mice. Cancer Sci. 2009;100(8):1510-1519.

\section{Dovepress}

patient perspectives such as quality of life, adherence and satisfaction The manuscript management system is completely online and includes a very quick and fair peer-review system, which is all easy to use. Visit http://www.dovepress.com/testimonials.php to read real quotes from published authors. 